\title{
PENGEMBANGAN FASILITAS INTERPRETASI BERBASIS QR CODE MENGGUNAKAN SYSTEM DEVELOPMENT LIFE CYCLE (SDLC): STUDI KASUS DI MUSEUM NEGERI SRI BADUGA, BANDUNG
}

\author{
Ludgardis Lipa* \\ Sekolah Tinggi Pariwisata Bandung \\ hlludgardi@gmail.com \\ Nurdin Hidayah \\ Sekolah Tinggi Pariwisata Bandung \\ nurdin@stp-bandung.ac.id \\ Dendy Sundayana \\ Sekolah Tinggi Pariwisata Bandung \\ dnd@stp-bandung.ac.id
}

\begin{abstract}
This study aims to develop an information system that specifically facilitates the interpretation of museum collections in order to optimize the delivery of collection information which in turn can provide a more experience for visitors. The research method used a qualitative approach with the System Development Life Cycle (SDLC) analysis technique. Data collection was carried out through documentation studies, interviews, and observations on each aspect of SDLC development. This study produces an information system in the form of a QR Code-based interpretation facility that is connected to information content on the website platform which contains information on collection themes such as descriptions, location of findings and collection classification which will add an augmented experience for visitors to the Sri Baduga State Museum.
\end{abstract}

Keywords: Augmented Experience, Sri Baduga State Museum, QR Code, System Development Life Cycle.

\begin{abstract}
Abstrak
Penelitian ini bertujuan untuk mengembangkan sistem informasi yang khusus memfasilitasi interpretasi koleksi museum agar dapat mengoptimalkan penyampaian informasi koleksi yang pada akhirnya dapat memberikan pengalaman lebih kepada pengunjung. Metode penelitian menggunakan pendekatan kualitatif dengan teknik analisis System Development Life Cycle (SDLC).Pengumpulan data dilakukan melalui studi dokumentasi, wawancara, dan observasi pada masing-masing aspek pengembagan SDLC. Penelitian ini menghasilkan sistem informasi berupa fasilitas interpretasi berbasis QR Code yang terhubung dengan konten informasi dalam flatform website yang berisi informasi mengenai tema-tema koleksi seperti deskripsi, lokasi temuan dan klasifikasi koleksi yang akan menambah augmented experience bagi para pengunjung Museum NegeriSri Baduga.
\end{abstract}

Kata kunci: Augmented Experience, Museum Negeri Sri Baduga, QR Code, System Development Life Cycle.

\section{A. PENDAHULUAN}

Pengembangan sektor pariwisata dituntut untuk beradaptasi dengan perkembangan teknologi dan informasi pada era digitalisasi yang mana telah ditanggapi oleh Kementrian Pariwisata Indonesia sejak tahun 2016 dalam Rapat Koordinasi Nasional Pariwisata ke-3 di Ecovention, Ecopark Ancol, Jakarta 
dengan mengusung tema Go Digital Be The Best. UNWTO kembali menegaskan pentingnya digitalisasi dalam peringatan World Tourism Day 2018 di Budapest, Hungaria melalui Tourism and The Digital Transformation. Salah satu bentuk peran penting digitalisasi adalah sistem informasi pariwisata. Dalam International Journals of Advanced Research in Computer Science and Software Engineering (2018: 97), Phru, Soe, dan Tin mendefenisikan sistem informasi pariwisata sebagai salah satu jenis sistem informasi yang didasari pada wisatawan, masyarakat perkotaan, administrasi lokal, bisnis lingkungan teknologi, lingkungan politik, lingkungan sosial, lingkungan ekonomi dan lingkungan ekologis.

Sistem informasi pariwisata merupakan suatu sistem berbantuan komputer yang memungkinkan wisatawan dapat mengakses informasi destinasi, akomodasi, transportasi dan layanan lainnya secara mudah dan cepat. Salah satu destinasi di Indonesia yang telah melibatkan teknologi informasi dan komunikasi dalam pengembangannya adalah Kota Bandung melalui pengembangan kota cerdas atau smart city yang didasarkan pada Masterplan Bandung Smart City. Dicantumkan dalam masterplan tersebutbahwa pengembangan smart city menekankan pentingnya sebuah inovasi dalam menyelesaikan persoalan atau permasalahan kota dengan memanfaatkan teknologi informasi dan komunikasi (TIK), sensor dan data analytic. Sebagai suatu destinasi, Kota Bandung memiliki berbagai macam daya tarik, salah satunya adalah permuseuman. Diantara museum-museum ini terdapat sebuah museum yang masih cukup minim keterlibatannya dengan teknologi yakni Museum Negeri Sri Baduga yang mana memiliki peran penting dalam mengedukasi pengunjung mengenai sejarah Jawa Barat melalui benda-benda koleksinya. Museum ini telah memiliki website dibawah Unit Pelaksana Teknis Dinas (UPTD) Pariwisata dan Kebudayaan Jawa Barat yang menyediakan beberapa informasi tentang museum seperti informasi kunjungan, informasi tentang UPTD, berita-berita yang berkaitan dengan kegiatan UPTD dan beberapa informasi lainnya, namun informasi mengenai koleksi belum memadai. Informasi koleksi yang tersedia hanya mengulas bahwa Museum Negeri Sri Baduga memiliki 10 jenis koleksi yakni geologika, biologika, heraldika, etnografika, keramologika, ilologika, arkeologika, historika, teknologika dan seni rupa tanpa menyajikan daftar dan uraian koleksi-koleksi dari kesepuluh jenis koleksi tersebut. Suatu museum memiliki peruntukan wajib sebagai sarana edukasi, hal ini dipertegas oleh UNESCO dan International Council of Museum/ICOM (2012: 4) yang mengemukakan bahwa pendidikan adalah salah satu kegiatan utama museum, bersamaan dengan pemeliharaan, penelitian dan penyajian benda-benda museum. Apabila ditinjau dari jumlah pengunjung, sejak tahun 2016 sampai 2018, angka kunjungan Museum Negeri Sri Baduga cenderung meningkat dengan pengunjung terbanyak berasal dari kalangan pelajar.

Menurut Permendikbud No 14 Tahun 2018, usia pelajar diklasifikasikan sebagai berikut: usia belajar di Sekolah Dasar dimulai pada usia 7 tahun, sedangkan siswa baru SMA dan sederajat maksimal berusia 21 tahun. Usia-usia tersebut dikategorikan sebagai generasi Z dan Alfa pada saat ini. Menurut Andrea, Gabriella, Tímea (2016: 93), Generasi Z adalah generasi internet atau Igeneration yang lahir diantara tahun 1995 sampai dengan tahun 2010 yang selalu online menggunakan perangkat mereka dan berinteraksi secara virtual tanpa henti. Generasi ini tidak paham akan konsep 'berusaha' dalam memperoleh sesuatu. Sedangkan Generasi Alfa menurut Susan Fourtanè dalam https://interestingengineering.com/ge neration-alpha-the-children-of-the- millennial (diakses pada 20 Februari 2019) merupakan generasi yang lahir diantara tahun 2010-2025, yang mana kelahirannya bersamaan dengan hadirnya Iphone, Ipad dan aplikasi- aplikasi lain. Generasi Alfa mampu secara alami menggunakan smartphone dan tablet serta merasa tidak dapat menjalani hidup tanpa perangkatperangkat tersebut.

Di samping itu, adapula beberapa pendapat pengunjung yang diperoleh ketika peneliti melakukan pra-survey, bahwa Museum Negeri Sri Baduga ini mempresentasikan hampir seluruh sejarah dan budaya Jawa Barat yang memiliki nilai edukasi yang sangat tinggi, namun tampak tidak menarik dan sangat 
membosankan padahal koleksinya cukup banyak (Fahri, mahasiswa Universitas Pendidikan Indonesia berusia 20 tahun). Vira Sani Putri, mahasiswa Telkom University berusia 21 tahun turut berkomentar bahwa saat ini kita berada pada era industri 4.0 yang mana teknologi bukanlah sesuatu yang sulit dan pada era ini juga dipenuhi oleh generasi yang tampak mendewa-dewakan gadgetnya ketika berurusan dengan pencarian informasi. Tapi di sisi lain, Museum Negeri Sri Baduga belum menyesuaikan diri dengan situasi ini sehingga informasi tidak tersampaikan secara optimal. Berdasarkan kondisi-kondisi ini, dapat dikatakan bahwa pengunjung Museum Negeri Sri Baduga didominasi oleh generasi yang bergantung pada teknologi seperti smartphone, tablet dan perangkat canggih lainnya serta cenderung ingin memperoleh sesuatu secara instant. Hal ini bertolak belakang dengan kondisi sistem informasi Museum Negeri Sri Baduga yang belum menyajikan informasi lengkap mengenai koleksi yang mana merupakan objek utama edukasi dari museum tersebut

UNESCO dan ICOM (2012: 5) sendiri memiliki tugas-tugas prioritas dalam pengembangan museum, salah satunya adalah penggunaan sumberdaya museum secara efisien untuk pengembangan pariwisata yang stabil dan seimbang termasuk pemanfaatan teknologi informasi dan komunikasi (TIK). Terdapat berbagai jenis teknologi yang dimanfaatkan oleh museum- museum dalam penyampaian informasi, diantaranya adalah QR (Quick Response) Code.

Winter (2010) mendefinisikan bahwa QR Code merupakan kode dua dimensi yang ditemukan di Jepang pada tahun 1994 oleh Denso Wave. Emek (2012: 1) menambahkan, QR Code mampu menyimpan lebih banyak data dan dengan cepat mengurai kode menjadi informasi serta memungkinkan pengguna untuk memperoleh informasi lebih dalam mengenai suatu objek dengan koneksi internet. Pilai, dkk (2017: 683) mengatakan bahwa pemanfaatan QR Code telah dilakukan oleh banyak museum di dunia, diantaranya:

a. The Cleveland Museum of Artdan Bologna's Museum of Archeology untuk melakukan tur audio mengenai informasi dari setiap koleksi pada museum.

b. China National Museum untuk menautkan konten multimedia dan informasi pameran.

c. Contemporary Art Museum and Galery Erartauntuk menampilkan informasi koleksi dalam berbagai bahasa.

d. London Museum untuk menampilkan film pendek mengenai benda yang peragakan.

Rima Wahyuningrum memaparkan bahwa Museum Wayang di kawasan Kota Tua telah menggunakan QR code untuk menampilkan informasi mengenai wayang. Lebih lanjut, dikatakan oleh Pelaksana Tugas, Kepala Dinas Pariwisata dan Kebudayaan DKI Jakarta bahwa dengan menggunakan QR code, wisatawan akan lebih cepat mengakses informasi secara paperless sehingga tetap bisa menjaga kelestarian lingkungan. Emek (2012: 4) menuturkan bahwa penggunaan QR code yang dilakukan oleh beberapa museum tersebut bertujuan untuk secara cepat mengakses informasi yang lebih dalam serta variatif karena QR code dapat memuat video, data, gambar dan atau kombinasi dari media presentasi. Keterangan dan situasi-situasi di atas menjadi acuan peneliti untuk mengembangkan suatu sistem informasi mengenai koleksi-koleksi yang dimiliki oleh Museum Negeri Sri Baduga agar dapat dinikmati oleh pengunjung. Pengembangan ini dilakukan melalui pemanfaatan WordPress Platform dan membentuk informasi tersebut menjadi QR code sebagai fasilitas interpretasi yang dapat dipindai oleh smartphone.

Penggunaan smartphone turut menjadi perhatian karena dilatarbelakangi oleh survei dari International Business Machine Corporation pada tahun 2017 yang menyatakan bahwa 75\% generasi Z memilih smartphone sebagai perangkat utama yang mereka gunakan (IBM Corporation, 2017: 4). Selain itu, dilansir oleh Dandy Cahyo (2019), bahwa sebagian besar populasi pengguna internet di Indonesia yang hanya mengakses melalui smartphone berasal dari usia muda yakni $80 \%$ pengguna berusia $15-17$ tahun dan 75\% pengguna berusia 18-24 tahun. Usia-usia ini termasuk dalam generasi Z. Lebih lanjut, 
pengembangan fasilitas interpretasi ini sejalan dengan rencana pembangunan Kawasan Strategis Pariwisata Kota Bandung yang tercantum dalam Peraturan Daerah Kota Bandung No. 10 Tahun 2013 tentang Rencana Induk Pembangunan Kepariwisataan Daerah (RIPARDA) Tahun 2012- 2025. Pada pasal 37, diterangkan bahwa Museum Negeri Sri Baduga merupakan salah satu daya tarik wisata sekunder dalam Kawasan Strategis Pariwisata Perkotaan Tegalega yang salah satu rencana pembangunannya adalah pengembangan fasilitas interpretasi dan infrastruktur pendukung. Dengan mengacu pada pertimbangan- pertimbangan tersebut, penelitian ini bertujuan untuk mengembangkan Sistem Informasi Fasilitas Interpretasi Berbasis QR Code Di Museum Negeri Sri Baduga, Kota Bandung, Provinsi Jawa Barat.

\section{B. KAJIAN LITERATUR}

Penelitian ini dilakukan dengan mengusung konsep utama System Development Life Cycle (SDLC) serta didukung dengan beberapa pengertian lain yakni pengertian wisata edukasi, museum, fasilitas interpretasi, sistem informasi pariwisata, WordPress Platform serta teknologi QR Code.

\section{System Development Life Cycle (SDLC)}

Everett dan McLeod, Jr (2007: 30) mengemukakan bahwa SDLC atau System/Software

Development Life Cycle merupakan tahapan-tahapan metodologi yang diikuti dalam proses pengembangan dan atau merevisi suatu sistem informasi. Boyde (2015: 49-50) membagi SDLC menjadi lima tahapan sebagai berikut:

a. Requirements/spesification

Tahap Requirements/spesification merupakan tahap persiapan yang dilakukan dalam beberapa sub-fase yakni initiation, conceptualization, requirements gathering and specifications dan planning

b. Designing

Tahap ini mendefinisi dan mendesain spesifikasi atau proses yang telah ditetapkan pada tahap sebelumnya.

c. Development/Implementation

Mentransformasi desain menjadi produk akhir (end-product).

d. Verification/Testing

Tahap ini mengkonfirmasi bahwa produk akhir yang dihasilkan telah sepenuhnya memenuhi fungsi yang diinginkan baik konfirmasi internal maupun konfirmasi perspektif pengguna mengenai kegunaan dan kenyamanan dari produk akhir tersebut.

e. Release, Maintenance and Support

Tahap ini merupakan tahap dimana produk akhir dihubungkan dengan lingkungan operasionalnya, memberi pelatihan kepada admin atau staf untuk menjalankan produk akhir serta melakukan perawatan end-product.

\section{Flowchart (Diagram Alir)}

Dalam proses mendesain alur, salah satu alat yang diperlukan adalah flowchart atau diagram alir yang digambarkan menggunakan simbol-simbol tertentu. Jalinus dan Ambiyar (2016:38- 41) 'Simbolsimbol flowchart meliputi: (1) flow direction symbols; (2) processing symbols; (3) input/output symbols. Flow direction symbols digunakan untuk menghubungkan simbol satu dengan yang lain dan disebut juga connecting line, sedangkan processing symbols menunjukkan jenis operasi pengolahan dalam suatu

proses/prosedur. Sementara, itu input/output symbols menunjukkan jenis peralatan yang digunakan sebagai media input atau output. 


\section{Metode Penelitian}

Penelitian ini dilakukan dengan menggunakan metode penelitian kualitatif dengan penetapan informan dilakukan menggunakan teknik purposive sampling. Para informan dibutuhkan dalam mengidentifikasi lebih jauh kesempatan untuk dikembangkannya suatu end-product pada sistem informasi di Museum Negeri Sri Baduga. Informan-informan tersebut adalah Kepala Seksi Museum Negeri Sri Baduga, Interpreter Museum Negeri Sri Baduga, Kepala Kelompok Kerja Koleksi Museum Negeri Sri Baduga, Kepala/Staf IT Museum Negeri Sri Baduga dan pengunjung. Pengumpulan data dalam penelitian ini menggunakan teknik observasi, wawancara dan studi dokumentasi. Observasi dilakukan untuk mengamati kondisi museum secara keseluruhan termasuk mengamati posisi koleksi dan letak fasilitas interpretasi dari koleksi tersebut, mengamati aktivitas konvensional yang dilakukan oleh pengunjung ketika menggunakan fasilitas interpretasi serta mengamati pemanfaatan sumberdaya sistem dan pemanfaatan teknologi pada fasilitas interpretasi.. Wawancara tepatnya wawancara semi standar dilakukan dengan mempersiapkan pokok-pokok pertanyaan untuk mengidentifikasi lebih jauh kesempatan untuk dikembangkannya suatu end-product pada sistem informasi di Museum Negeri Sri Baduga. Sedangkan studi dokumentasi dilakukan untukmengumpulkan data-data berupa profil Museum Negeri Sri Baduga, data kunjungan dan data-data koleksi dari museum tersebut. Teknik analisis yang digunakan adalah System Development Life Cycle (SDLC). Mulyani (2016: 24) mengemukakan bahwa "SDLC adalah sebuah proses logika yang digunakan oleh seorang system analist untuk mengembangkan sebuah sistem informasi" dengan salah satu alat yang diperlukan dalam mendesain alur sistem informasi adalah flowchart atau diagram alir.

\section{Hasil dan Pembahasan}

Museum Negeri Sri Baduga merupakan museum tingkat provinsi yang bernaung di bawah Departemen Pendidikan dan Kebudayaan. Museum ini berada di jalan B.K.R No. 185, berposisi tepat diseberang lapang Tugu Bandung Lautan Api, Tegallega, Kota Bandung. Jumlah benda koleksi Museum Negeri Sri Baduga per tahun anggaran 2018 adalah 7.046 koleksi yang terklasifikasi atas koleksi Geologika, Biologika, Etnografika, Arkeologika, Historika, Numismatika dan Heraldika, Filologika, Keramologika, Seni Rupa, dan Teknologika. Dari sekian banyaknya koleksi, hanya sebagian kecil yang ditampilkan di ruang pamer yakni 258 koleksi karena keterbatasan tempat, sehingga sisanya masih disimpan di ruang penyimpanan. Data koleksi ruang pamer telah tersedia dan dapat dipublikasikan pada website dengan mengecualikan koleksi masterpiece sebanyak 58 koleksi. Pengecualian ini didasari pada pertimbangan keamanan dan eksklusivitas koleksi unggulan tersebut.

\section{Requirement/Specification}

\section{a. Initiation}

Pernyataan-pernyataan baik dari pihak pengelola maupun pengunjung memperlihatkan bahwa Museum Negeri Sri Baduga membutuhkan pengembangan sistem informasi di bagian interpretasi koleksi. Pengelola membutuhkan pengembangan tersebut agar museum dapat mengimbangi situasi perkembangan generasi saat ini sehingga museum tetap bisa membantu pembentukan rasa cinta dan hormat daripada generasi saat ini terhadap sejarah dan budaya Jawa Barat serta mempertahankan kelayakan museum yang telah bersertifikat ISO (International Organization for Standardization) 9001: 2015 melalui peningkatan fasilitas di museum. Berdasar pada kebutuhan ini, pengelola pun telah melakukan pengajuan proposal terkait pengembangan sistem informasi, salah satunya adalah sistem informasi koleksi kepada Dinas Pariwisata dan Kebudayaan yang telah disertakan dalam agenda pembahasan tim akselerasi yang dibentuk oleh 
Gubernur dan mendapat keterangan positif yakni pengembangan tersebut dapat segera direalisasikan selambat-lambatnya di tahun 2021. Sejalan dengan pernyataan pengelola tersebut, pengunjung memperlihatkan kebutuhan mereka melalui perilaku ingin memperoleh informasi koleksi yang detail baik di luar museum maupun didalam museum meskipun dengan waktu yang terbatas serta pemberian saran dan harapan pengunjung akan aktivitas ringan tambahan yang melibatkan pemanfaatan teknologi ketika menjelajahi museum, seperti adanya fasilitas audio visual yang berisi penjelasan setiap koleksi di ruang pamer museum. Oleh karena itu, pengembangan sistem informasi fasilitas interpretasi berbasis QR Code yang menjadi fokus dalam penelitian ini dapat dijadikan sebagai langkah awal untuk menjawab kebutuhan pengelola dan merealisasikan saran serta harapan pengunjung.

\section{b. Conceptualization}

Sasaran dan batasan pengembangan sistem dipaparkan sebagai berikut, sistem yang dikembangkan terfokus pada interpretasi koleksi museum yang diawali dengan membangun website pada wordpressplatform; web hosting disediakan oleh Niagahoster; informasi yang akan ditampilkan dalam web page terdiri atas tiga informasi inti yakni deskripsi, lokasi temuan dan klasifikasi koleksi; dan pekerjaan dilakukan sampai pembentukan Uniform Resource Locator (URL) dari web page menjadi QR Code.

\section{c. Requirements Gathering and Specifications}

Kebutuhan Fungsional (Functional Requirements) sistem terdiri dari, admin dapat memasukkan data-data koleksi yang meliputi, deskripsi koleksi, lokasi temuan koleksi dan klasifikasi koleksi yang disertakan dengan gambar dari koleksi; admin dapat mengelompokkan data koleksi berdasarkan kategori tertentu, seperti klasifikasi koleksi; admin dapat mengedit atau mengubah dan menghapus data dan gambar koleksi: admin dapat membentuk Uniform Resource Locator (URL) dari web page menjadi QR Code berupa gambar; pengguna (pengunjung) dapat memindai gambar QR Code ketika berkunjung ke museum; pengguna (pengunjung) dapat menyimpan gambar QR Code dalam perangkatnya (smartphone, tablet, laptop) dan memindainya ketika diperlukan.

Kebutuhan Non-Fungsional (Non-Functional Requirement) terdiri dari; sistem operasi ketika pengembangan adalah Windows 10 Pro yang telah terverifikasi oleh akun microsoft; koneksi internet; software pendukung yang digunakan adalah WordPress Platform versi 5.2.3 dan QR Code Generator online (https://www.the-qrcode- Generator.com/); keamanan telah dilengkapi dengan Secure Socket Layer (SSL) dan password admin; informasi yang ditampilkan kepada pengguna (pengunjung) ketika gambar QR Code dipindai adalah informasi URL suatu web page yang berisi informasi koleksi (dengan sekali klik 'akses' atau 'ok')

\section{d. Planning}

Dalam tahap perencanaan akhir ini, terdapat beberapa kebutuhan yang diperlukan untuk mendukung pengembangan sistem informasi fasilitas interpretasi koleksi di Museum Negeri Sri Baduga yang terdiri dari; ruang lingkup sistem operasi yang dimiliki museum adalah Windows 7 Home Basic; data yang dimasukkan dalam sistem terdiri dari 200 data koleksi; waktu pengerjaan yang dibutuhkan 3 bulan; staf/ pengelola IT yang dimiliki oleh museum terdiri dari seorang staf dengan dasar atau latar belakang Program dan Jaringan dan dua orang lainnya tidak memiliki dasar atau latar belakang IT, namun telah mampu mengelola website dan sistem informasi lainnya yang tidak memerlukan keahlian coding yakni pengelolaan 
website berbasis Content Management System; museum menggunakanvsistem jaringan internet yang disediakan oleh Skyline baik di area non- public, termasuk ruang IT dan area public termasuk ruang pamer dari lantai satu sampai lantai tiga; dan biaya yang diperlukan per tanggal 26 September 2019 sebesar Rp 696.346 dengan rincian: Paket Pelajar untuk museumsribaduga.site berdurasi 6 bulan seharga Rp 503.800, pendaftaran domain museumsribaduga.site berdurasi 1 tahun seharga Rp 14.000, Comodo positivessl untuk museumsribaduga.site berdurasi 1 tahun seharga Rp 115.000 serta ditambah PPN Rp 63.280 dan kode unik Rp 266.

\section{Designing}

Alat yang dibutuhkan untuk mendefinisi dan mendesain alur sistem informasi ini adalah flowchart atau diagaram alir. Terdapat beberapa flowchart yang masing-masingnya menggambarkan suatu proses tertentu, yakni: Flowchart Pengaktifan Domain Melalui Web Hosting Niagahoster; Flowchart Instalasi WordPress Menggunakan Softaculous App Installer; Flowchart Masuk Admin dashboard Pada WordPress; Flowchart Pengaturan Tema Website Pada WordPress; Flowchart Aktivasi Plugin Website Pada WordPress; Flowchart Penambahan Kategori Website Pada WordPress; Flowchart Penambahan dan Pengaturan Menu Website Pada WordPress; Flowchart Publikasi Artikel Koleksi; dan Flowchart Pembentukan QR Code Koleksi.

\section{Development}

Tahap pengembangan sistem dilakukan untuk menerjemahkan rancangan proses pada flowchart menjadi wujud produk akhir yang lebih nyata yakni berupa QR Code koleksi, yang mana proses pengembangan tersebut disajikan dalam bentuk deskripsi yang lebih jelas dan mudah diikuti. Deskripsi proses ini dibuat agar dapat menjadi panduan pengelolaan bagi staf/pengelola sistem informasi di Museum Negeri Sri Baduga. Tahap pengembangan ini dibagi atas yakni tahap pengaktifan domain melalui web hosting Niagahoster, tahap pembangunan website pada WordPress Platform dan tahap pembentukan QR Code Koleksi seperti pada gambar 1.

\section{Gambar 1}

Website dan QR Code Koleksi Museum Negeri Sri Baduga
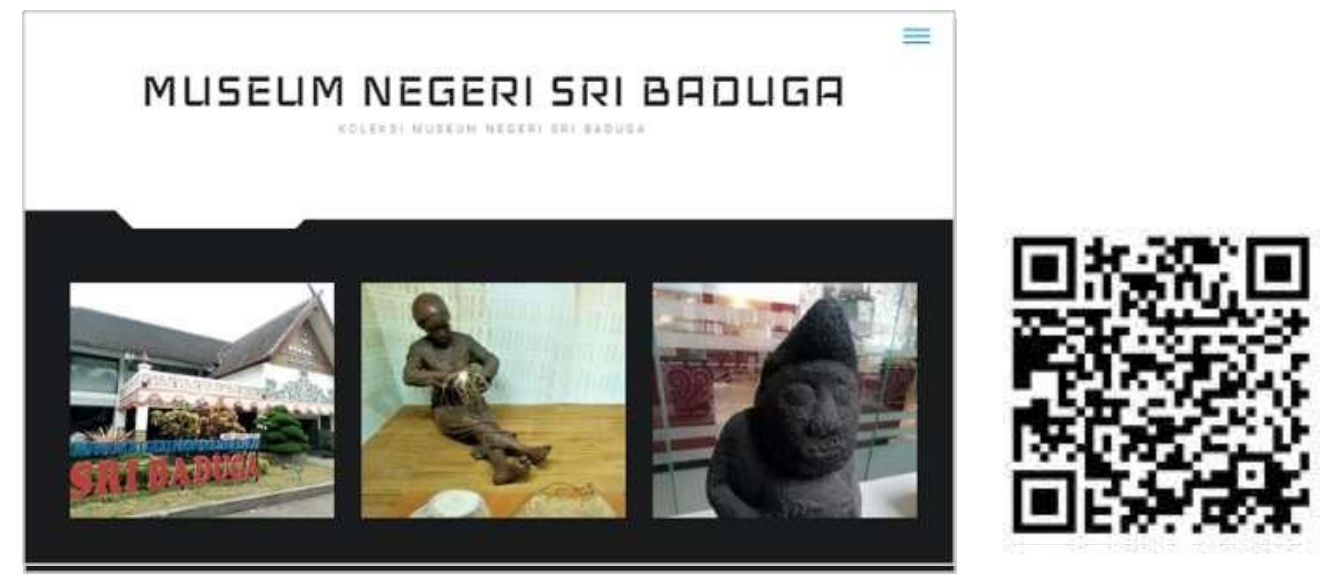


\section{E. SIMPULAN}

Museum Negeri Sri Baduga memerlukan sistem informasi yang dapat menjadi media pemenuhan kebutuhan informasi koleksi bagi pengunjung, sekaligus membantu pengelola untuk terus mampu mengimbangi perkembangan teknologi di zaman sekarang. Oleh karena itu, pengembangan sistem informasi fasilitas interpretasi berbasis QR Code yang menjadi fokus dalam penelitian ini dapat dikembangkan sebagai langkah awal untuk menjawab kebutuhan pengelola dan merealisasikan saran serta harapan-harapan pengunjung. Persiapan yang dilakukan dalam pengembangan sistem informasi dimulai dari pengonsepan sampai mempersiapkan kebutuhan sistem informasi, termasuk kebutuhan data. Pemanfaatan WordPress Platform dalam membangun website menjadi pilihan dengan banyak fasilitas berupa fitur-fitur yang memudahkan pengaturan baik pengaturan tampilan website maupun proses publikasi artikel koleksi.

Terdapat berbagai proses yang dilakukan untuk membangun website dimulai dari pengaktifan domain website sampai dengan pembentukan QR Code sebagai fasilitas interpretasi di Museum Negeri Sri Baduga. Proses- proses ini didefinisi dan dirancang menggunakan alat yang disebut flowchart atau diagram alir, tepatnya flowchart sistem.

Pengembangan sistem informasi ini menghasilkan sebuah website yang berdomain museumsribaduga.site. Website ini khusus berisi informasi koleksi yang meliputi deskripsi, lokasi temuan dan klasifikasi koleksi. Setiap halaman artikel koleksi ini dibentuk menjadi QR Code sebagai salah satu bentuk fasilitas interpretasi di Museum Negeri Sri Baduga.

\section{REKOMENDASI}

Penambahan Ekstra Deskripsi Terdapat banyak koleksi yang masih sangat minim isi deskripsinya sehingga membuat informasi koleksi menjadi kurang menarik. Kapasitas penyimpanan tidak terbatas yang ditawarkan oleh Niagahoster sangat memungkinkan penyimpanan informasi koleksi yang lebih banyak tentang suatu koleksi, sehingga pengunjung tidak merasa sia-sia ketika memindai QR Code yang ditampilkan pada suatu koleksi. Penambahan dilakukan dengan memanfaatkan fitur widget button pada elementor (wordpress plugin).

Penambahan Media Audio Visual Data kunjungan Museum Negeri Sri Baduga mencatat bahwa sejak tahun 2016 sampai 2018, angka kunjungan Museum Negeri Sri Baduga cenderung meningkat dengan pengunjung terbanyak berasal dari kalangan pelajar. Hal ini menunjukkan bahwa Museum Negeri Sri Baduga cukup berhasil dalam menjalankan fungsinya sebagai sarana. edukasi. Lebih lanjut, sebagian besar informan pengunjung yang diwawancara mengharapkan adanya aktivitas ringan tambahan yang melibatkan pemanfaatan teknologi ketika menjelajahi museum, seperti audio visual mengenai suatu koleksi. Berdasarkan kedua kondisi ini, penambahan audio visual sebagai media pembelajaran dapat dijadikan sebagai pilihan pengembangan sistem informasi berikutnya

\section{DAFTAR PUSTAKA}

David, N., Susan, A. M., Ross, K. D. (2012). Natural Area Tourism: Ecology, Impacts and Management (2nd Ed). Ontario: Channel View Publications

Djam'an, S dan Aan, K. (2013).

Metodologi Penelitian Kualitatif. Bandung: Alfabeta 
Gerald, D. E dan Raymond, M,Jr. (2007). Software Testing: Testing Across the Entire Software Development Life Cycle.Hoboken,NJ: John Wiley \& Sons Inc.

Guo Yixin. (2000). Vocation Economy. Guangzhou: Guangzhou Economics Press

IBM Corporation. (2017). Uniquely Generation Z: What brands should know about today's youngest consumers. New York: Somers

J.B. Dixit \& Raj, K. (2007). Structured System Analysis and Design. New Delhi: Laxmi Publications (P) LTD.

Joshua, B. (2014). A Down-To- Earth Guide To SDLC Project Management (2nd Ed): Getting your system / software development life cycle project successfully across the line using PMBOK adaptively: Author

Judith, S. (2011). Introducing the QR Code: The Reality and the Magic: ProofreadNZ Limited

Maryna S, dkk. 2012. Role of Museums in Education and Cultural Tourism Development: Policy Brief. Kiev: UNESCO Moscow Office and the Intergovernmental Foundation for Educational, Scientific and Cultural Cooperation for CIS countries (IFESCCO)

Mick, W. (2011). Scan Me - Everybody's Guide to the Magical World of Qr Codes. Napa: Westsong Publishing.

Nicolae, S. (2015). Short WordPress Guide For Beginners: Author

Rohmat, T. (2018). Pengantar Sistem Informasi. Jakarta: Mitra Wacana Media

\section{Sumber dari Buku Online}

Maniah dan Hamidin, D. (2017). Analisis dan Perancangan Sistem Informasi: Pembahasan Secara Praktis Dengan Contoh Kasus. Yogyakarta: Deepublish. Diakses dari :

https://books.google.co.id/books?\%20id=MjxyDwAAQBAJ\&pg=PA35\%20\&dq=pengertia $\mathrm{n}+$ kebutuhan+fun $\% 20 \mathrm{gsional}+$ dan + non + fungsional + sis $\% 20$ tem\&hl=en\&sa $=X \& v e d=0$ ahU K\%20EwjS_uu12u3kAhXBh3AKHW\%20XBCW8Q6AEIjjAA\#v=onepage\%20\&q=pengertia $\mathrm{n} \% 20$ kebutuhan $\% 2 \% 200$ fungsional\%20dan\%20non\%20f\%20ungsional $\% 20$ sistem \&f=f alse

\section{Sumber Jurnal}

Bencsik, A., Horváth-Csikós G., Juhász T. (2016). Y and Z Generations at Workplaces. Journal of Competitiveness, 8 (3), 90-106. Diambil dari : https://doi.org/10.7441/joc.2016. 03.06

Mehmet E. (2012). Usage of QR Code in Tourism Industry diambil dari : http://openaccess.dogus.edu.tr/bit\%20stream/handle/11376/108/Mehme\%20tEmek.p df?sequence $=1$

Pillai, dkk. (2017). Application of QR Codes in Tourism Industry: A Review of Literature diambil dari

http://www.ijcta.com/documents/\%20volumes/vol8issue6/ijcta2017080\%20608.pdf

Phru et al. (2018). The Tourism Management Information System for Selection Beaches in Myanmar. International Journal of Advanced Research in Computer Science and Software Engineering, $\quad 96-99 \quad$ diambil dari https://www.ijarcsse.com/index.p\%20hp/ijarcsse/article/download/840/\%20487

Rita, A. (2014). Perancangan Data Flow Diagram Untuk Sistem Informasi Sekolah (Studi Kasus Pada SMA Pembangunan Laboratorium UNP) dalam Jurnal TEKNOIF. Diakses dari : https://ejournal.itp.ac.id/index.ph p/tinformatika/article/viewFile/1 84/181

\section{Sumber Majalah dan Surat Kabar}

Dandy, C. (2019, Februari 20). Diakses dari : http://dewina- journal.foutap.com/penggunaansmartphone-di-indonesia-tahun- 2017/

Kathryn, D. (2015). Diakses dari : https://www.forbes.com/sites/kathryndill/2015/11/06/7things-employers- should-know-about-the-gen-z-workforce/\#4f2f9646fad7 
Rima, W. (2019, Februari 25). Diakses dari : https://megapolitan.kompas.com/read/2018/12/18/07005211/permudah- wisatawanakses-informasi-museum-wayang-kini-pakai-qr-code

\section{Sumber dari Publikasi Pemerintah dan Website Institusi}

Janry, H. U. P. S. (2014). Konsep Dasar Sistem Informasi. Diakses dari Universitas Terbuka, situs web http://repository.ut.ac.id/3921/2/ADPG4442- M1.pdf

Kementrian Hukum dan HAM RI. (2013). Peraturan Daerah Kota Bandung No. 10 Tahun 2013 tentang Rencana Induk Pembangunan Kepariwisataan Daerah (RIPARDA) Tahun 20122025. Diakses dari http://peraturan.go.id/perda/kota- bandung-nomor-1-tahun2013.html 